\title{
Interactive comment on "An integrated modeling framework for coevolution and feedback loops of nexus across economy, ecology and food systems based on the sustainable development of water resources" by Yaogeng Tan et al.
}

\section{Yaogeng Tan et al.}

\section{4@hhu.edu.cn}

Received and published: 12 July 2020

\section{Dear referee,}

Thank you for supporting the decent contributions of this paper. Also, I'm greatly appreciated for your comments on our manuscript because it can substantially help improve the quality of the paper. I carefully read your comments about this paper and they can, in my opinion, categorized into five concerns. In short, it refers to (i) the economic module of the nexus should contain the farmer's profits; (ii) optimal model development; (iii)

Printer-friendly version

Discussion paper 
the limitation of the development model that should be acknowledged; (iv) uncertainty of the conceptual framework modeling; (v) English grammar. These main concerns you mentioned are very useful for the paper as well as my future research careers, and I will carefully revise the paper to improve its quality.

Below please find my responses to your comments and the revised directions of the manuscript that we are going to resubmit.

(i) the economic module of the nexus should contain the farmer's profits (corresponding to the first paragraph of your comment)

I completely agree with your opinion because the agricultural economy is also of great significance to socio development and it is reflected by the profit of farmers and primary industry products. This is what the paper lacks and we will add it in the revised paper. However, the source of agricultural profit is still crops and meat production, which is an important part of the agricultural module. It is undoubtedly that humans cannot survive without crops. Generally speaking, crops and meat are usually sold in the farmer's markets and they get profit by customers buying those crops and meat to simulating consumption (just take an example). Therefore, the maximizing profit of farmers, as well as primary industry products are still based on crops.

Of course, if the model only considers the crop yield in the agricultural sector, it is definitely unrealistic as you mentioned in your comment because the farmer's response has no economic basis. Crop is important, but it is not the only. The farmer's profit, as well as primary industry product, should be fully considered as it is an important part of the economic module that the current paper lacks. We will consider this part of analysis into both the model setup and SDD assessment and add it to the model when revising the paper, and better demonstrate the economy behaviors by revealing its mutual interaction between other modules/components to make the model more integrated and realistic, and further adjust the demonstration of feedback loops and results.

Printer-friendly version

Discussion paper 
(ii) Optimal model development (corresponding to the second paragraph of your comment)

The paper developed the optimal model to achieve the goal of sustainable development, considering three aspects: ecology, economy, and food. The main part of this research is water resources, and an adequate supply of water resources is the key insurance of social activities. Although each objective function seems to be linear, when combining to an integrated model with the optimal programming solution, as well as the system dynamic model that is also complex and nonlinear, in my opinion, the total method may appear to be nonlinear. Moreover, the uncertainty analysis (see (iv)) will also be considered when revising the paper, which will strengthen the model reliability. Agricultural (crop) demand mainly contains irrigation that is mainly determined by precipitation that is random and cannot be determined by human being, which is different from household and industrial water demand. Also, economic incentives are also key sources of agricultural water demand. I agree with your opinion about the nonlinear assumption. For the concern of your agricultural sector, the farmer's profit will be considered in the model to address the profit basis (as stated in (i)).

(iii) The limitation of the development model that should be acknowledged (corresponding to the 3rd and 4th paragraph of your comment)

I have read thoroughly about the reference you offered: Pindyck 2015, and indeed the statement he/she argued is reasonable. Pindyck stated the IAM modeling limitations and took the relationship between climate change and GDP as an example. The main limitation is the flaws of the models that sometimes must be developed to overcome a certain problem. The main source of the flaws is usually the uncertainties of a certain modeling approach that stems from the definitions and assumptions of certain equations, concepts, or parameters that are usually diverse from different researchers. The author took the examples of (i) damage function of DICE (Dynamic Integrated Climate and Economy) model that has both quadratic and cubic assumptions; (ii) "Limits to Growth" debate that slow population growth to prevent the natural resources from run-

Printer-friendly version

Discussion paper 
ning out, which is likely to ignore the basic economics that the price of natural resources will rise to decline their uses. Therefore, the author stated that the limitations of a certain modeling approach should be acknowledged before adopting the model to prevent it from abusing, but he/she did not completely deny the application of the model. For example. IAM model can be valuable as analytical and pedagogical devices to help us better understand climate dynamics and climate-economy interactions, as well as some of the uncertainties involved.

Similarly, the above statement can be also adopted in my study. It is rather necessary to assess the feedback loop and future changes to better understand the achievements of sustainable development but, we are unable to know what will happen in the next one, two or more decades unless we are prophets. Therefore, the "modeling" approach is emerged to "simulate" the possible changes in the future and many researches have also developed such models to simulate future trends (Feng et al., 2016; 2019). However, it certainly refers to somewhat unreliable and uncertainties that stem from the difficulty of being a common sense to a certain issue or concept (as stated by Pindyck that the assessment of social cost of carbon (SSC) is quite different $(\$ 39, \$ 11$ even $\$ 200$ ), which increases the uncertainties of the model, and the different values of SCC are from different scholars). Although it cannot give a policy direction as is usually need to simplify the basic principles, it does not mean that it is of no use, at least it can help us better understand how to achieve the goal of sustainable development. It doesn't mean to give up entirely on estimating the sustainable development status more generally (Pindyck, 2015). Therefore, we need to take advantage of the positive effect as much as possible of a certain model that is, although, usually double-sided. To consider the limitation of the modeling approach and revise it in my paper, I will add the above statement at the end of "result and discussion" section to highlight the limitation to discuss in-depth about the paper to better acknowledge the limitations to readers in the revised paper to prevent misleading.

(iv) Uncertainty of the conceptual framework modeling (corresponding to your last para-

Printer-friendly version

Discussion paper
Interactive

comment 
As stated before, models are usually a flaw because it contains uncertainty (Pindyck, 2015) and may be responsible for simulation errors. Therefore, as you mentioned in the comments, uncertainty analysis is necessary to improve the reliability of the model. I agree with your suggestion and have read the references you provided to me. According to Herman et al., (2015), many methods were tackled to deal with the model uncertainties. For multiobjective models, Herman stated, "the pre-specification of alternatives, preference weighting, the most important (sensitive) factors, or performance thresholds may produce unintended consequences for decision making." In other words, preference weighting is one of the most important sources of uncertainty. Also, Kasprzyk et al., (2013) stated that MORDM approach is also a method to deal with the uncertainties, in which alternatives are first generated by multiobjective search prior to their evaluation in deeply uncertain states of the world. The alternatives are generated by LHS sample and Pareto frontiers for tradeoffs between objectives. Also, Liu et al., (2019) also started the multiobjective model refers to the wind-photovoltaichydropower system that corresponds to the three objectives, and uncertainties are also referred by the different weights of objectives that are addressed by Pareto frontiers.

If uncertainties are analyzed on a full scale in this paper, it is clearly beyond the scope of this paper as uncertainty itself can be written by another paper, which is another story. Also, the paper will be too long. However, uncertainty is of great necessity to improve the model's reliability and therefore, must be considered. In this paper, the EEF nexus model includes three objectives: economy, ecology and food, and uncertainty can be also reflected by weighting factors and tradeoffs between objectives (Liu et al., 2019). Actually, in the current paper, I mentioned this issue in Section 2.2.3 but maybe it's not so clear. Therefore, in the revised manuscript, I will strengthen the statement of uncertainty and tradeoff issue, and the mutual relationship \& tradeoff between objectives will be further analyzed to improve the model reliability, which gives more references for policymakers.

Printer-friendly version

Discussion paper 
(v) English Grammar (minor comments) I will read the manuscript thoroughly and check the grammar everywhere in the revised paper as much as possible.

Yours, sincerely,

Yaogeng Tan and co-authors

References

Feng, M., Liu, P., Guo, S., David, J. Y., Cheng, L., Yang, G., \& Xie, A.: Adapting reservoir operations to the nexus across water supply, power generation, and environment systems: An explanatory tool for policymakers. J Hydrol, 574, 257-275, 2019.

Feng, M., Liu, P., Li, Z., Zhang, J., Liu, D., \& Xiong, L.: Modeling the nexus across water supply, power generation and environment systems using the system dynamics approach: Hehuang Region, China. J Hydrol, 543, 344-359, 2016.

Herman, J.D., Reed, Zeff, H.B., Characklis, G.W., 2015. How Should Robustness Be Defined for Water Systems Planning under Change? J. Water Resour. Plan. Manag. 141, 04015012.

Kasprzyk, J. R., Nataraj, S., Reed, P. M., and Lempert, R. J. (2013). "Many objective robust decisions making for complex environmental systems undergoing change."

Liu, W., Zhu, F., Chen, J., Wang, H., Xu, B., Song, P., ... \& Li, J. (2019). Multi-objective optimization scheduling of wind-photovoltaic-hydropower systems considering riverine ecosystem. Energy conversion and management, 196, 32-43.

Pindyck, R.S., 2015. The Use and Misuse of Models for Climate Policy (Working Paper No. 21097). National Bureau of Economic Research.

Interactive comment on Hydrol. Earth Syst. Sci. Discuss., https://doi.org/10.5194/hess-2020328, 2020. 